\title{
Article \\ Roma Socioeconomic Status Has a Higher Impact on Smoking Behaviour than Genetic Susceptibility
}

\author{
Mohammed Merzah ${ }^{1,2}$, Zsigmond Kósa ${ }^{3}$, János Sándor ${ }^{1}$, Shewaye Natae ${ }^{1,2}$, Péter Pikó 4 (D), Róza Ádány ${ }^{1,4}$ (D) \\ and Szilvia Fiatal 1 ,*
}

Citation: Merzah, M.; Kósa, Z.; Sándor, J.; Natae, S.; Pikó, P.; Ádány, R.; Fiatal, S. Roma Socioeconomic Status Has a Higher Impact on Smoking Behaviour than Genetic Susceptibility. Int. J. Environ. Res. Public Health 2021, 18, 3206. https:// doi.org/10.3390/ijerph18063206

Academic Editor: Paul B. Tchounwou

Received: 27 January 2021

Accepted: 18 March 2021

Published: 19 March 2021

Publisher's Note: MDPI stays neutral with regard to jurisdictional claims in published maps and institutional affiliations.

Copyright: (c) 2021 by the authors. Licensee MDPI, Basel, Switzerland. This article is an open access article distributed under the terms and conditions of the Creative Commons Attribution (CC BY) license (https:// creativecommons.org/licenses/by/ $4.0 /)$.
1 Department of Public Health and Epidemiology, Faculty of Medicine, University of Debrecen, 4032 Debrecen, Hungary; mohammed.merzah@med.unideb.hu (M.M.); sandor.janos@med.unideb.hu (J.S.); natae.shewaye@med.unideb.hu (S.N.); adany.roza@med.unideb.hu (R.Á.)

2 Doctoral School of Health Sciences, University of Debrecen, 4032 Debrecen, Hungary

3 Department of Health Methodology and Public Health, Faculty of Health, University of Debrecen, 4400 Nyíregyháza, Hungary; kosa.zsigmond@foh.unideb.hu

4 MTA-DE Public Health Research Group, University of Debrecen, 4032 Debrecen, Hungary; piko.peter@med.unideb.hu

* Correspondence: fiatal.szilvia@med.unideb.hu

\begin{abstract}
It is a matter of speculation whether the high prevalence of smoking among Hungarian Roma (HR) is related to genetic, gene-environmental interactions or cultural factors. Our aim is to compare the genetic susceptibility and possible effects of determinants associated with smoking behaviours in the Hungarian general (HG) and Roma populations. A complex health survey including three pillars (questionnaire, physical and laboratory examinations) was carried out $\left(\mathrm{N}_{\mathrm{HG}}=412\right.$ and $\mathrm{N}_{\mathrm{HR}}=402$ ). Risk allele frequencies of ten single-nucleotide polymorphisms (SNPs) were compared, and their combined effect was estimated by computing unweighted and weighted genetic risk scores (GRS, wGRS). The effects of genetic and environmental factors were investigated in regression analyses after confounders were introduced. Socio-economic status (SES) was calculated based on the Kuppuswamy scale 2019. Risk allele frequencies of only four SNPs were found to be different between populations $(p<0.01)$. Median values of GRS did not differ, while the wGRS median was slightly higher among Roma individuals (5.2 vs. $4.9 ; p=0.02$ ). Roma individuals were more likely to be heavy smokers $\left(\mathrm{OR}_{\text {males }}=2.05,95 \% \mathrm{CI}\right.$ [1.47-2.86]; $\mathrm{OR}_{\text {females }}=1.89,95 \% \mathrm{CI}$ [1.58-2.25]. Smokers have lower SES compared to never smokers (SES $\beta_{\mathrm{HR}}=-0.039, p=0.023 ; \beta_{\mathrm{HG}}=-0.010, p=0.049$ ). An inverse relationship was found between SES and smoking behaviours $(p<0.0001)$ and was found to be a better predictor of smoking behaviours than genetic susceptibility. Our study findings suggest that the high prevalence of smoking behaviours and nicotine-dependence were not revealed to have a genetic susceptibility among HR individuals; therefore, the highest efforts should be focused on targeting SES-related factors in the Roma population. Strengths of the study: This is the first study carried out to investigate and detect the most relevant factors and the possible genetic background of the extremely high prevalence of smoking based in the Roma population. Limitations of the study: No standard instrument has been used to assess the intensity of addiction to nicotine. Because of some participants' unwillingness to define themselves as Roma, the overall HR population was not represented by the sample of this study.
\end{abstract}

Keywords: smoking behaviours; genetic susceptibility; Roma; socioeconomic status; SNP

\section{Background}

Smoking is one of the main risk factors for non-communicable diseases (NCDs) [1] and is a preventable risk factor for numerous diseases, especially cardiovascular diseases (CVDs) [2]. Smoking behaviour is influenced by genetic and environmental factors and their interactions [3]. Despite the best efforts of global health organizations, which aim to warn populations about the hazards of smoking, its consumption has sharply increased 
worldwide [4]. The highest rate of tobacco use in 2018 was observed in European countries; the prevalence was $29 \%$ among European adults aged more than 15 years, which is estimated to be more than 200 million smokers, among which $35 \%$ were women [5]. The prevalence of smoking in Hungary was $28 \%$ in the total population, and only less than a quarter of women and a third of men were regular smokers in 2014 based on the Hungarian European Health Interview Survey [6], while the estimated cigarettes smoked per day (CPD) among Hungarians aged $\geq 15$ was 23.0 [5]. Of note, the prevalence of smoking differs significantly by age group [7]. Based on a recent epidemiological study carried out in Hungary, the smoking rate was highest among the $35-44$ age group (37.5\%), followed by the 18-24 age group (26.9\%) who smoke on a daily basis. However, occasional smoking was most prevalent in the younger age group [8]. The elderly, aged 55-65 years-old, were on the top list of former smokers and the $45-55$ age group were more likely to have ceased smoking [8].

Roma, the largest minority population in Hungary, is the most marginalized ethnicity (estimated population is 8-12 million) in Central-Eastern European countries. They suffer social exclusion, which intensely affects their health outcomes [9]. Higher burdens of disease, low life expectancy, low socioeconomic status, and low education are common among the Roma minority, independent of the county in which they live [10-12]. Hungarian Roma (HR) individuals have a higher rate of smoking compared to the Hungarian general (HG) population [11,12]. The prevalence of tobacco consumption by the HR adult population is estimated between $41-72 \%$, which is two to five times higher than in the HG adult population. Remarkably, approximately $51.1 \%$ of HR women are smokers and very unlikely to quit; $70.3 \%$ of them did not cease smoking during pregnancy [13-15]. Furthermore, a study has shown that Roma population were more likely to initiate smoking at early age [16]. A study, conducted on UK individuals aimed to determine the influences of Body Mass Index (BMI) on smoking habits and intensity, suggests that higher adiposity has a strong influence on smoking behaviours and also associated with smoking initiation at younger ages [17]. Among Roma population, a shift from traditional lifestyles characterized by higher caloric intakes and more sedentary lifestyle could lead change in BMI distribution, with obesity becoming significantly more common in the younger Roma population $[12,18,19]$.

Several studies have revealed that genetic characteristics might exist behind the differences in smoking habits/behaviours, and some genetic backgrounds could be exponents towards smoking. Moreover, previous studies provided robust evidence that the high prevalence of smoking behaviours and nicotine dependence was related to genetic susceptibility [20-22]. Recent studies have shown that the majority of risk alleles of selected non-communicable diseases have been accumulated in the Roma population $[18,23]$, which support the hypothesis that the health status of Roma is determined by a complex set of inheritable factors.

The smoking prevalence in the Roma population is significantly higher than in the majority population of countries where this has been studied (Croatia, Czech Republic, Hungary, Italy, Lithuania, Macedonia, Slovakia, and Slovenia), even after adjusting for socio-economic factors $[10-14,24,25]$. If inheritable factors are responsible for differences in smoking patterns of this ethnicity [26], this is the population that one may expect to find it given the high prevalence of smoking and strong nicotine dependence, their distinct ethnic and genetic identity, and high levels of consanguinity [27,28].

In addition to genetic susceptibility, socio-economic status (SES) was found to be a determining factor for smoking habits. The smoking rate is higher among those living in lower SES in developing countries; similarly, in developed countries, smoking rates are $60 \%$ higher among those who have experienced different forms of disadvantage than that of among the affluent [29]. Former research revealed that SES is a strong determinant of the health of the Roma population. It was found to be associated with less healthy behaviours such as unhealthful eating, alcohol initiation, and early smoking [13,29].

To improve the health of the Roma minority, conducting studies on selected diseases and health-related behaviours is a priority. The question of whether genetic or environ- 
mental factors are more responsible for the higher smoking prevalence in this minority is still open [28]. Hence, this present study was designed to highlight the roles of genetic susceptibility and other possible determinants in the high prevalence of smoking behaviours among the HR population.

\section{Materials and Methods}

\subsection{Study Design and Population}

Formerly, a complex health survey was designed to create a complex database for comparative and association studies to better understand the background of the very unfavourable health of Roma individuals, especially the high burden of cardiometabolic diseases. This cross-sectional study had three main pillars of data (questionnaire-based, physical and laboratory examinations) among the HG and HR adults (20-64 years). Eighthundred thirty-two participants were recruited from both populations (417 HG and $415 \mathrm{HR}$ ) [19]. For the present study, eighteen participants (five HG and $13 \mathrm{HR}$ ) were excluded due to missing anthropometric parameters. In addition to creating a complex database, a DNA biobank was also created from the collected data and blood samples.

\subsection{Patient and Public Involvement}

No patient involved.

\subsection{Statistical Analysis}

Plink v.1.9 [30] and Statistical Packages for Social Sciences (SPSS v.25, IBM Corporation: Armonk, NY, USA) [31] were used to analyse the data. To describe the relationships of genotypes with smoking phenotypes (see below) and other demographic variables, a chi-square test was used. Linear regression was applied to predict the best indicator with quantitative smoking behaviours (Model I for CPD; and Model II for age at smoking initiation). To determine the best predictor of smoking status (smoker vs. non-smoker), binary regression models were carried out where (SES), sex, age, BMI, and genetic risk score (GRS) (Model III) or weighted genetic risk score (wGRS) (Model IV) were set as independent variables. Furthermore, multinomial regression analysis was performed to predict smoking behaviours (never smoker, former smoker, moderate smoker, and heavy smoker), as a dependent variable; whereas SES, sex, age, ethnicity, BMI, and GRS (Model V) or wGRS (Model VI) were set as independent variables. A Benjamini-Hochberg multiple correction test was applied to control the false discovery result (FDR) and to compute the adjusted significant results.

\subsection{Single-Nucleotide Polymorphism (SNPS) Selection}

The criteria of SNP selection were described elsewhere [28]. In brief, as a first step, 33 SNPs were selected, based on a literature search on PubMed, as they show a strength effect on smoking behaviours and a consistence pertinent to smoking intensity. All selected SNPs were collected from studies that have a statistically acceptable sample size. Ultimately, only 10 SNPs were included in this present study; the others were excluded for various reasons (unavailability of estimated effect size from genome wide association studies (GWASs) or to avoid multicollinearity based on the fact that only one SNP per linkage disequilibrium (LD) block could be involved).

\subsection{DNA Isolation and Genotyping}

DNA isolation and genotyping method were exposed elsewhere [28]. In brief, DNA preparation was carried out from EDTA-anticoagulation blood samples on the day of sample collection. From plasma samples, DNA were isolated using MagNA Pure LC DNA Isolation Kit-Large Volume (Roche Diagnostics, Basel, Switzerland) according to the manufacturer's instructions. Genotyping was performed on a MassARRAY platform (Sequenom Inc., San Diego, CA, USA) with iPLEX Gold chemistry by the Mutation Analysis Facility 
service provider (MAF, Karolinska Institute, Solna, Sweden). Validation, concordance analysis, and quality control were conducted by the Facility according to their protocols.

\subsection{Genetic Risk Score}

Weighted genetic risk scores (wGRS) were calculated based on the risk allele odds ratios of previous studies [20,32-36]. Based on the number of risk alleles carried, each person was assigned a score, where " 0 " indicated no risk allele, " 1 " indicated those who were heterozygous for a risk allele, and " 2 " was assigned to participants who were homozygous for a risk allele. Equation (1) was used for wGRS calculation, where $\left(W_{O R}\right)$ was derived from the risk coefficients of each risk allele based on the relative effective size determined previously, and $\left(X_{i}\right)$ was annotated to the number of effective alleles carried by each individual:

$$
w G R S=\sum_{i=1}^{I} W_{O R} X_{i}
$$

The unweighted genetic risk score was calculated for each individual based on Equation (2) where $G_{i}$ is the number of risk alleles for each SNP. Then, all scores for each person of the ten SNPs were summed with the assumption that all SNPs have a similar effect:

$$
G R S=\sum_{i=1}^{I} G_{i}
$$

\subsection{Smoking Phenotypes}

Qualitative smoking behaviours were classified into four categories. Never smoker (NSM) was defined as a person who smoked $\leq 100$ cigarettes in his/her entire life. Participants who consumed $\leq 5 \mathrm{CPD}$ or who had smoked more than 100 cigarettes in their lifetime but have been smoke-free for at least one year were defined as former smokers (FSM). Moderate smokers (MSM) were participants who smoked $6 \leq \mathrm{CPD}$ but $<20$, while participants who smoked $\geq 20 \mathrm{CPD}$ were classified as heavy smokers (HSM) [12]. Later during the analysis, the former, moderate, and heavy smokers were combined and categorized as smokers. Furthermore, quantitative smoking behaviours (CPD, and age at smoking initiation) were also included in this study.

\subsection{Hardy-Weinberg Equilibrium (HWE)}

Deviation of the genotype distributions from Hardy-Weinberg Equilibrium (HWE) was inspected for HG and HR population separately. The rs3762611 was excluded from further analysis due to failing to follow HWE (Supplementary Table S1). In addition, rs4105144 could not be genotyped due to poor clustering and was not possible to call correctly according to the MAF service provider.

\subsection{Socioeconomic Status (SES)}

SES was characterized by using the modified Kuppuswamy Scale 2019. The criteria for calculation were described elsewhere [37]. Briefly, SES were categorized into five groups, upper, upper-middle, lower-middle, upper-lower and lower, based on education level, occupation, and monthly family income.

\subsection{Ethical Approval}

The Committee of the Hungarian Scientific Council on Health approved the protocol (61327-2017/EKU). All subjects agreed to participate in this study by signing a written informed consent.

\section{Results}

Descriptive statistics were performed to summarize demographic data of participants. Females of both populations represented $64 \%$ of participants; among them, $56.5 \%$ were 
HR individuals. Three-quarters of the study populations were aged $<50$ years. More than two-thirds of HG individuals were non-smokers, while almost the same proportion of the HR individuals were smokers. A highly significant difference was detected regarding smoking status among the study populations $(p$-value $<0.001)$. HR males and females were (OR $=1.9$ and 2.1, respectively) more likely to be smokers compared to their HG counterparts (Supplementary Table S2). Lower socioeconomic level was reported among HR individuals, which was highly significant $(p$-value $<0.0001)$ compared to HG individuals. A total of $78.6 \%$ of HR individuals were living in the lower to upper-middle SES categories (See Table 1).

Table 1. Characteristics of the study populations.

\begin{tabular}{|c|c|c|c|c|c|}
\hline & & \multicolumn{2}{|c|}{ Population } & \multirow[b]{2}{*}{$x^{2}$} & \multirow[b]{2}{*}{$p$-Value } \\
\hline \multicolumn{2}{|c|}{ Variables } & HG $(N=412)$ & HR $(N=402)$ & & \\
\hline Sex & $\begin{array}{c}\text { Male } \\
\text { Female }\end{array}$ & $\begin{array}{l}186(45.1) \\
226(54.9)\end{array}$ & $\begin{array}{l}106(26.4) \\
296(73.6)\end{array}$ & 28.699 & $<0.0001$ \\
\hline Age (years) & $\begin{array}{c}20-29 \\
30-39 \\
40-49 \\
50-59 \\
\geq 60\end{array}$ & $\begin{array}{c}70(16.9) \\
76(18.4) \\
117(28.4) \\
91(22.2) \\
58(14.1)\end{array}$ & $\begin{array}{c}79(19.3) \\
81(19.8) \\
103(25.1) \\
95(23.2) \\
44(10.8)\end{array}$ & 9.187 & 0.102 \\
\hline $\begin{array}{l}\text { Socioeconomic } \\
\text { Status (SES) }\end{array}$ & $\begin{array}{c}\text { Lower } \\
\text { Upper lower } \\
\text { Lower middle } \\
\text { Upper middle } \\
\text { Upper }\end{array}$ & $\begin{array}{c}0(0) \\
69(16.7) \\
175(42.5) \\
150(36.4) \\
18(4.4)\end{array}$ & $\begin{array}{c}21(5.2) \\
106(26.4) \\
189(47.0) \\
86(21.4) \\
0(0)\end{array}$ & 26.983 & $<0.0001$ \\
\hline Smoking Status & $\begin{array}{c}\text { Smoker } \\
\text { Non-smoker }\end{array}$ & $\begin{array}{l}135(32.8) \\
277(67.2)\end{array}$ & $\begin{array}{l}262(65.2) \\
140(34.8)\end{array}$ & 86.497 & $<0.0001$ \\
\hline
\end{tabular}

Bold font highlights significant differences between populations. HG = Hungarian general; HR = Hungarian Roma.

Risk allele frequencies among HG and HR populations differed significantly for rs2673931, rs6517442, and rs2235186 at the $<0.05$ level and for rs578776 at the $<0.0001$ level (Supplementary Table S3). After adjusting and removing all missing genotypes, there were still no differences in the results found among all significant SNPs. Conversely, some differences were obtained after performing correction tests among males and females separately. The frequencies of rs578776, rs6517442, and rs2235186 differed significantly at a level of $p<0.05$ among males before adjusting $(0.021,0.036$, and 0.015 respectively), while they were insignificant after adjusting. Among females, however, the frequency of rs578776 was highly significant even after multiple correction test $(p<0.0001)$ (Supplementary Tables S4 and S5).

A chi-square test was performed to detect the relationship between genotype and smoking status in the study samples and separately in each population with smoking behaviours. For smoking status, the additive model shows significant relationships for rs16969968-A, rs2036534-T, rs2235186-A, rs578776-G, and rs6517442-C (Table 2). Homozygous and heterozygous statuses for risk alleles for all significant SNPs were highly frequent among HR smokers (Table 2). Regarding smoking behaviours, however, the additive model revealed that no SNP was significant among HR individuals, while the only significant (at $p<0.001$ ) result obtained among HG individuals was for the additive model of rs2235186-A with smoking behaviours (Supplementary Tables S6 and S7). 
Table 2. Genotype by smoking status in study populations $(\mathrm{N}=814)$.

\begin{tabular}{|c|c|c|c|c|c|c|c|}
\hline \multirow{2}{*}{ SNPs } & \multirow{2}{*}{ Gene } & \multirow{2}{*}{ Genotype } & \multicolumn{2}{|c|}{ HG $(\mathrm{N}=412)$} & \multicolumn{2}{|c|}{ HR $(N=402)$} & \multirow{2}{*}{$p$-Value } \\
\hline & & & SM \% & NSM \% & SM \% & NSM \% & \\
\hline \multirow[t]{3}{*}{ rs10490162-T } & NRXN1 & $\mathrm{CC}$ & 0.5 & 1.0 & 0.8 & 0.0 & 0.271 \\
\hline & & $\mathrm{TC}$ & 4.4 & 14.7 & 11.0 & 5.9 & \\
\hline & & $\mathrm{T} \mathrm{T}$ & 27.9 & 51.5 & 53.2 & 29.2 & \\
\hline \multirow[t]{3}{*}{ rs16969968-A } & CHRNA5 & A A & 3.4 & 7.3 & 6.4 & 5.6 & 0.031 \\
\hline & & G A & 18.8 & 30.3 & 28.5 & 13.7 & \\
\hline & & G G & 10.5 & 29.6 & 30.3 & 15.5 & \\
\hline \multirow[t]{3}{*}{ rs2036534-T } & AGPHD1 & $\mathrm{CC}$ & 0.2 & 3.2 & 4.1 & 2.3 & 0.039 \\
\hline & & $\mathrm{CT}$ & 9.6 & 23.8 & 24.2 & 12.0 & \\
\hline & & $\mathrm{T} \mathrm{T}$ & 22.8 & 40.4 & 36.9 & 20.6 & \\
\hline \multirow[t]{3}{*}{ rs2235186-A } & $M A O A$ & A A & 7.1 & 11.3 & 15.0 & 7.4 & $<0.0001$ \\
\hline & & A G & 9.3 & 16.9 & 26.4 & 10.7 & \\
\hline & & G G & 16.2 & 39.2 & 23.9 & 16.8 & \\
\hline \multirow[t]{3}{*}{ rs2673931-T } & TRPC7 & $\mathrm{CC}$ & 5.2 & 8.8 & 13.2 & 7.1 & 0.121 \\
\hline & & $\mathrm{CT}$ & 16.2 & 31.9 & 33.0 & 18.5 & \\
\hline & & $\mathrm{T} \mathrm{T}$ & 11.3 & 26.5 & 19.0 & 9.1 & \\
\hline \multirow[t]{3}{*}{ rs4142041-G } & CTNNA3 & A A & 13.4 & 21.8 & 28.1 & 15.1 & 0.300 \\
\hline & & A G & 15.6 & 36.1 & 28.8 & 15.8 & \\
\hline & & G G & 4.2 & 8.9 & 7.9 & 4.3 & \\
\hline \multirow[t]{3}{*}{ rs578776-G } & CHRNA3 & A A & 0.7 & 5.7 & 11.6 & 7.5 & $<0.0001$ \\
\hline & & G A & 13.9 & 25.4 & 30.2 & 12.9 & \\
\hline & & G G & 18.4 & 35.8 & 23.2 & 14.7 & \\
\hline \multirow[t]{3}{*}{ rs6517442-C } & KCNJ6 & $\mathrm{CC}$ & 3.7 & 4.9 & 6.3 & 5.1 & 0.008 \\
\hline & & $\mathrm{TC}$ & 10.5 & 31.1 & 32.2 & 14.5 & \\
\hline & & $\mathrm{T} \mathrm{T}$ & 18.6 & 31.3 & 26.6 & 15.2 & \\
\hline
\end{tabular}

Bold font highlights significant differences. SM = smokers; NSM = non-smokers, HG = Hungarian general; HR = Hungarian Roma. Risk allele is written beside each SNP.

Generally, the average CPD was higher among HR individuals (12 \pm 13$)$ than among HG individuals $(5 \pm 9)$. Males of both populations consumed more CPD compared to females; however, HR males (14 \pm 7 ) consumed double the CPD compared to HG males $(6 \pm 5)$. HG females smoked ( $4 \pm 4)$ one-third the CPD compared to their counterparts from the HR population $(12 \pm 5)$. In addition, $\mathrm{CPD}$ was high among dominant homozygous genotypes for rs6517442-C, rs16969968-A, rs2235186-A, rs578776-G, and rs4142041-G alleles. Additive-dominant models for rs10490162-T and rs2673931-T were related to high numbers of cigarettes smoked per day in the whole population (Supplementary Figure S1a,b).

The association of CPD with genotype was varied if we consider study populations separately. Genotypes with risk alleles for some SNPs were highly significantly associated with average CPD only in HG individuals, while others were associated only in HR individuals. In general, HG individuals who carried either homozygous or heterozygous risk alleles of 6 SNPs out of eight had higher smoke rates. In contrast, four SNPs out of eight were interconnected with high smoke rates among HR individuals (Supplementary Figure S2(a1,a2,b1,b2)).

Ages at smoking initiation among HR and HG individuals were not different. The mean ages at smoking initiation were $16 \pm 1.774$ years and $17 \pm 0.308$ years for HR and HG populations, respectively. Dominant homozygous and heterozygous at rs10490162-T and rs6517442-C were related with an early age at smoking initiation. However, in the whole study population, only dominant homozygous genotypes at rs16969968-A, rs2235186-A, and rs4142041-G were related to an early age at smoking initiation (Supplementary Figure S3a,b).

Oddly, HR individuals who carried dominant homozygous or heterozygous risk alleles for all SNPs except rs2673931-T began smoking at an early age (Supplementary Figure S4(b1,b2)). Nevertheless, an early age at smoking initiation was related to homozygous risk alleles being carried among HG individuals for six SNPs (Supplementary Figure S4(a1,a2)). Remarkably, HR individuals who carried dominant homozygous alleles at rs6517442 began smoking at an early age ( $15 \pm 0.8)$ (Supplementary Figure S4(b1)), while a 
dominant homozygous allele at rs16969968 was linked to an early age of smoking initiation (15.6 \pm 0.07$)$ among HG individuals (Supplementary Figure S4(a2)).

The median and interquartile range (IQR) of GRS were equivalent for HR and HG individuals (median $=9, p=0.618$; IQR $=7-10$ ). However, the wGRS median for HR individuals was slightly higher (median $=5.2)$ than that for HG individuals (median $=4.9)$, with $p=0.02$. The IQRs of wGRS were 3 to 5 for HG individuals and 4 to 6 for HR individuals (Supplementary Figure S5); consequently, wGRS were right-shifted among HR individuals. Heavy smokers were 1.07 among HR individuals and 1.02 among HG individuals and were more likely to have higher GRS compared to other smokers. The wGRS was higher among heavy smokers of the $\mathrm{HG}$ population $(\mathrm{OR}=1.34 ; \mathrm{CI}=0.32-0.97)$; conversely, lower wGRS among heavy smokers the of HR population were noted compared to other smokers of the same population $(\mathrm{OR}=0.94 ; \mathrm{CI}=0.86-1.42)$. See Supplementary Table S8.

Different sets of regression models were set up to identify the best predictors behind smoking behaviours. Linear regression (Model I \& II) was performed to predict the best factors that might associate with quantitative smoking behaviours (cigarettes per day, $\mathrm{CPD}$, and age at smoking initiation). Model I shows that HR individuals were 33\% $(p<0.001)$ more likely to smoke more cigarettes than HG individuals. In relation to age at smoking initiation, $\mathrm{HR}$ individuals were more likely to start smoking at an early age (standardized $\beta=-0.23, p<0.001$ ). In addition, a lower BMI was found among people who smoke more and initiate smoking at early ages with respect to the other classifications; however, gender was significantly associated with CPD but not with smoking initiation, (Supplementary Tables S9 and S10).

Smoking status was fixed as a dependent variable in a binary regression analysis, where socioeconomic status (SES), sex, age, BMI, and GRS (for Model III-Table 3A) and wGRS (for Model IV-Table 3B) were set as independent variables. These models show that SES was the best predictor for smoking behaviours, with a significant $p<0.05$ among populations, separately. Smokers have a lower SES compared to never smokers of both populations (SES $\beta=-0.039, p=0.023$ for HR; $\beta=-0.010, p=0.049$ for HG). Furthermore, HR smokers were found to have a lower BMI compared to those who are non-smokers $(\beta=-0.150, p=0.004)$.

Table 3. Association of SES with smoking status by study group.

\begin{tabular}{|c|c|c|c|c|c|c|}
\hline \multicolumn{7}{|c|}{$\mathbf{A}$} \\
\hline & \multicolumn{2}{|c|}{ Hungarian Roma ( $n=402$ ) } & \multicolumn{4}{|c|}{ Hungarian General $(n=412)$} \\
\hline & $\beta$ & $95 \%$ CI & $p$-Value & $\beta$ & $95 \%$ CI & $p$-Value \\
\hline SES & -0.039 & $0.023-0.026$ & 0.022 & -0.037 & $0.044-0.064$ & 0.046 \\
\hline GRS & -0.003 & $-0.039-0.034$ & 0.148 & 0.034 & $-0.03-0097$ & 0.302 \\
\hline Sex & -0.026 & $-0.124-0.236$ & 0.609 & -0.236 & $-0.588-0.116$ & 0.198 \\
\hline Age & -0.058 & $-0.091-0.039$ & 0.267 & 0.061 & $-0.048-0.17$ & 0.272 \\
\hline \multirow[t]{4}{*}{ BMI } & -0.150 & $-0.259-0.031$ & 0.004 & -0.124 & $-0.314-0.067$ & 0.203 \\
\hline & \multicolumn{6}{|c|}{ B } \\
\hline & \multicolumn{3}{|c|}{ Hungarian Roma ( $n=402)$} & \multicolumn{3}{|c|}{ Hungarian General $(n=412)$} \\
\hline & $\beta$ & $95 \% \mathrm{CI}$ & $p$-Value & $\beta$ & $95 \% \mathrm{CI}$ & $p$-Value \\
\hline SES & -0.039 & $0.052-0.072$ & 0.023 & -0.010 & $0.059-0.069$ & 0.049 \\
\hline wGRS & -0.163 & $-0.203-0.088$ & 0.095 & 0.065 & $-0.040-0.171$ & 0.157 \\
\hline Sex & -0.026 & $-0.203-0.631$ & 0.355 & -0.263 & $-0.064-0.077$ & 0.129 \\
\hline Age & -0.058 & $-0.229-0.068$ & 0.288 & 0.072 & $-0.046-0.190$ & 0.231 \\
\hline BMI & -0.150 & $\begin{array}{c}-0.441- \\
-0.081\end{array}$ & 0.004 & -0.150 & $-0.346-0.046$ & 0.134 \\
\hline
\end{tabular}

Bold font means significant. $R^{2}=0.22(A), R^{2}=0.23(B)$; smoking status (smokers and non-smokers) was fixed as a dependent variable. $\mathrm{SES}=$ socioeconomic status; GRS = genetic risk score; $\mathrm{BMI}=$ body mass index; wGRS = weighted genetic risk score. Adjusted regression analysis was used to evaluate the association where the model was adjusted for SES, sex, age, BMI and GRS (A) and with wGRS (B). 
Multinomial logistic regression analysis was calculated to predict smoking behaviours based on genetic risk score (GRS) for Model V, weighted genetic risk score (wGRS) for Model VI, and SES, age, BMI, sex and population (HG fixed as a reference category). The regression equation was significant $(p<0.0001)$, with an $R^{2}$ of 0.176 . Smoking behaviours were significantly predicted based on socioeconomic status (SES) and population. An inverse relationship was found between SES categories and smoking behaviours, $(p<0.0001)$; moreover, HG individuals were less likely to be smokers than HR individuals $(p<0.05)$ after adjusting for age, BMI, and sex and genetic factors. (Table 4). In sum, SES was found to be a better predictor of smoking behaviours than genetic susceptibility.

Table 4. Association of smoking behaviours with SES and other variables.

\begin{tabular}{|c|c|c|c|c|c|c|c|}
\hline \multirow{2}{*}{$\begin{array}{l}\text { Smoking } \\
\text { Behaviours }\end{array}$} & & \multicolumn{3}{|c|}{ Model V } & \multicolumn{3}{|c|}{ Model VI } \\
\hline & & OR & $95 \%$ CI & $p$-Value & OR & $95 \% \mathrm{CI}$ & $p$-Value \\
\hline \multirow{8}{*}{$\begin{array}{l}\text { Former } \\
\text { Smoker }\end{array}$} & GRSs & 1.033 & $0.702-1.521$ & 0.870 & 1.011 & $0.762-1.520$ & 0.675 \\
\hline & SES = upper lower & 1.005 & $1.000-1.088$ & $<0.001$ & 1.335 & $1.296-1.951$ & $<0.001$ \\
\hline & SES = lower middle & 1.059 & $1.042-1.221$ & $<0.001$ & 1.482 & $1.045-1.700$ & $<0.001$ \\
\hline & SES = upper middle & 1.357 & $1.350-1.753$ & $<0.001$ & 1.561 & $1.451-1.601$ & $<0.001$ \\
\hline & Age & 1.274 & $0.887-1.83$ & 0.190 & 1.275 & $0.885-1.826$ & 0.194 \\
\hline & BMI & 0.847 & $0.535-1.342$ & 0.480 & 0.847 & $0.534-1.341$ & 0.477 \\
\hline & {$[$ Sex $=$ Male $]$} & 0.538 & $0.173-1.677$ & 0.285 & 0.539 & $0.173-1.677$ & 0.285 \\
\hline & [Population = HG] & 0.287 & 0.091-1.403 & 0.014 & 0.285 & $0.272-1.265$ & 0.015 \\
\hline \multirow{8}{*}{$\begin{array}{l}\text { Moderate } \\
\text { Smoker }\end{array}$} & GRSs & 1.027 & $0.865-1.218$ & 0.764 & 1.025 & $0.817-1.106$ & 0.514 \\
\hline & SES = upper lower & 1.991 & $1.885-2.557$ & $<0.001$ & 1.274 & $1.111-1.278$ & $<0.001$ \\
\hline & SES = lower middle & 1.253 & $1.152-1.778$ & $<0.001$ & 1.095 & $1.091-1.619$ & $<0.001$ \\
\hline & $\mathrm{SES}=$ upper middle & 0.385 & $0.285-0.850$ & $<0.001$ & 0.625 & $0.625-0.962$ & $<0.001$ \\
\hline & Age & 1.063 & $0.904-1.250$ & 0.457 & 0.904 & $0.907-1.254$ & 0.436 \\
\hline & BMI & 0.746 & $0.604-0.922$ & 0.007 & 0.604 & $0.604-0.921$ & 0.006 \\
\hline & {$[$ Sex $=$ Male $]$} & 0.853 & $0.543-1.340$ & 0.490 & 0.854 & $0.543-1.342$ & 0.493 \\
\hline & [Population = HG] & 0.383 & $0.292-4.023$ & $<0.001$ & 0.543 & $0.236-4.130$ & $<0.001$ \\
\hline \multirow{8}{*}{$\begin{array}{l}\text { Heavy } \\
\text { Smoker }\end{array}$} & GRSs & 1.027 & $0.88-1.199$ & 0.737 & 1.045 & 0.911-1.199 & 0.527 \\
\hline & SES $=$ upper lower & 1.979 & $1.155-2.177$ & $<0.001$ & 1.662 & $1.228-1.688$ & $<0.001$ \\
\hline & SES = lower middle & 1.113 & $1.098-1.855$ & $<0.001$ & 1.892 & $1.706-1.905$ & $<0.001$ \\
\hline & SES = upper middle & 0.885 & $0.655-1.022$ & $<0.001$ & 0.976 & $0.679-0.987$ & $<0.001$ \\
\hline & Age & 0.983 & $0.85-1.1370$ & 0.816 & 0.981 & $0.85-1.1370$ & 0.818 \\
\hline & BMI & 0.734 & $0.609-0.884$ & 0.001 & 0.733 & $0.608-0.883$ & 0.001 \\
\hline & {$[$ Sex $=$ Male $]$} & 1.622 & $1.097-2.400$ & 0.015 & 1.623 & $1.095-2.397$ & 0.016 \\
\hline & [Population = HG] & 0.151 & $0.109-4.996$ & $<0.001$ & 0.151 & $0.109-4.934$ & $<0.001$ \\
\hline
\end{tabular}

Bold font highlights significant results. Never smoker was set as a reference. SES = socioeconomic status; GRSs = genetic risk scores; $\mathrm{BMI}=$ body mass index; $\mathrm{HG}=$ Hungarian General. Model V = using genetic risk score (GRS) with SES, BMI, age, sex, and population as independent variables. Model VI = using weighted genetic risk score (wGRS) with SES, BMI, age, sex, and population as independent variables. SES = upper was set as a reference category; the lower category of SES was removed from the table, as it was considered as a redundant because no single HG subject was indicated in this category. The $\mathrm{R}^{2}$ of the association was 0.176 .

\section{Discussion}

People living in segregated areas not only experience social exclusion [26,38], but also genetic susceptibility, which might increase their risk for some unhealthy behaviours or diseases [38,39]. Knowing the genetic characteristics behind smoking behaviours is crucial so that new interventions can be utilized for smoking cessation. To the best of our knowledge, no previous study has been performed on genetic comparisons of the qualitative and quantitative smoking behaviours among Hungarians. A genetic load comparison was performed in our former study, as no load of genetic susceptibility was found related to increased smoking rate in HR individuals, but phenotypic data were not available. Therefore, this study was conducted to demonstrate the genetic background and the predictors behind smoking behaviours among those populations with the availability of phenotypic data. Our study findings suggest that the high prevalence of smoking 
behaviours and nicotine-dependence were not revealed to have a genetic susceptibility among HR individuals.

Equivalent GRS-medians were found in both populations. Based on the wGRS, HR individuals had slightly higher median-risk scores than HG individuals. Weighted and un-weighted genetic risk scores were not related to smoking behaviours, while ethnicity and socioeconomic status (SES) were significantly linked to smoking behaviours. Although GRSs were equivalent in study populations, heavy smokers still had higher risk scores. This might be due to the selected SNPs, as most of them were related to nicotine dependence, which is higher among heavy smokers [40]. Therefore, further studies including more SNPs related to smoking behaviours are required.

As the HR population lives in segregated areas with economic difficulties, the environmental and cultural factors might be dominant towards smoking habits. In general, tobacco use follows clear socio-demographic patterns and is becoming increasingly concentrated in lower socio-economic group [29,41]. Smokers across Europe were more likely to be unemployed, self-employed or manual workers; the latter were the most prevalent smokers among the employees ( $40 \%$ smoke). Correspondingly, tobacco use has a strong connection with lower levels of educational attainment [29]. A Roma health report, issued by European Union, reveals that these patterns are also reflected in Roma populations, where smoking prevalence is typically high, with smoking initiation at younger age and tendency to smoke more cigarettes than the non-Roma population [29,42].

Moreover, SES proved to be a dominant factor that might influence HR health and lifestyles $[13,43,44]$. HR individuals living in economic difficulty not only have a higher smoking rate but also a lower chance to quit smoking $[15,45,46]$. Living in a lower economic status increases the likelihood of being a smoker (Supplementary Table S11); this finding is supported by others $[9,13,29,44,46]$. Sixty-five percent of HR individuals were smokers, from which $77 \%$ were living in lower-middle categories of SES, and from which $50 \%$ were heavy smokers. This shows the highly correlated link between smoking behaviours and SES. In other words, the lower the economic status in which the HR individuals live, the higher the prevalence of heavy smoking habits would be. Therefore, categorizing strategies of interventions and disease prevention as alternative implications could be achieved through revealing the effects of segregation. Public health efforts should be dedicated to detecting social/cultural barriers to reducing smoking rates.

It is clear that many policies that have led to the decrease in smoking rate in the general population were less successful in the HR [11]. A qualitative study, conducted in Slovenia, described smoking as a feature of Roma ethnic, cultural, and individual identity since the cigarette introduced by older family members to younger ones, considering it as a part of "growing up" [47]. Hence, qualitative research on understanding the barriers to reduction in smoking rate among HR are urgently needed. It is noteworthy that most Roma individuals reject to support policies related to tobacco-control-measures [11]. However, studying the extent to which Roma populations feel marginalized and discriminated by public authorities must take full account, and messages must be developed through a shared process with Roma participation, in ways that avoid stigmatization.

Heavy smokers were assumed to be nicotine-dependent [39,44,48]; based on that assumption, we considered participants as heavy smokers based on the number of cigarettes smoked per day, which was the major limitation of this study. Instead, the Fagerstrom Test for Nicotine Dependence (FND) [49], the Wisconsin Inventory of Smoking Dependence [50] or the Nicotine Dependence Syndrome Scale [51] would have been useful in our study, as nicotine dependence phenotypes might be measured accurately. Another limitation of this study was that the overall HR population was not represented by the sample of this study. Attributable to some participants' unwillingness to define themselves as HR, this might contribute to include some HR individuals being classified under the HG group, which might have consequences on some underestimations of genetic susceptibility outcomes.

Altogether, this is primarily a study of the differentiation of genetic characteristics of the qualitative and quantitative smoking behaviours among HG and HR populations. Our 
hypothesis, which assumed that HR individuals are genetically susceptible to smoking behaviours, was rejected. Therefore, efforts of future studies should be focused on nongenetic factors, especially SES determinants, while even further studies on genetic factors that predispose ethnic minorities to a higher risk of smoking are also needed and might contribute to tobacco control.

Supplementary Materials: The following are available online at https:/ /www.mdpi.com/1660-460 1/18/6/3206/s1. Table S1: Hardy-Weinberg equilibrium for Hungarian Roma; Table S2: Smoking status among both populations based on gender; Table S3: Differences in risk allele frequencies between study populations; Table S4: Risk allele differences for males of both populations; Table S5: Risk allele differences for females of both populations; Table S6: Genotype by smoking behaviours in general population; Table S7: Genotype by smoking behaviours in the Roma population; Table S8: GRSs and Smoking behaviours; Table S9: Predicted model on cigarette per day in both populations; Table S10: Regression model on age-imitation of smoking in both populations; Table S11: Socioeconomic status according to smoking status in both population; Figure S1: Cigarette per day (CPD) by genotype in the whole study sample; Figure S2: Cigarette per day (CPD) by genotype among HG $(a 1,2),(b 1,2)$ among HR; Figure S3: Age at smoking initiation by genotype; Figure S4: Age at smoking initiation by genotypes among HG $(a 1,2),(b 1,2)$ among HR; Figure S5: Frequency distributions of GRS and wGRS based on populations.

Author Contributions: Conceptualization, R.Á.; writing, preparing the manuscript, and interpreting results, M.M. and S.F.; statistical analysis, M.M. and S.F.; methodology and sample/data collection, S.N., P.P., Z.K. and J.S.; reviewing, editing, and finalizing the manuscript, S.F. and R.Á. All authors have read and agreed to the published version of the manuscript.

Funding: This study was financed by the European Union under the European Regional Development Fund (GINOP-2.3.2-15-2016-00005), the Hungarian Academy of Sciences (MTA11010 and TK2016-78) and the National Research, Development and Innovation Office, Hungarian Ministry of Innovation and Technology (grant No OTKA 135784).

Institutional Review Board Statement: The Committee of the Hungarian Scientific Council on Health approved the protocol (61327-2017/EKU).

Informed Consent Statement: Informed consent was obtained from all subjects involved in the study.

Data Availability Statement: No additional data available.

Conflicts of Interest: No conflict of interest.

\section{References}

1. WHO Regional Office for Europe. Noncommunicable Diseases and Air Pollution. WHO Europe High-Level Conference Noncommunicable Disable Time to Deliver Meet NCD Targets to Achieve Sustain Development Goals Europe. 2019. Available online: http:/ / www.euro.who.int/pubrequest (accessed on 11 December 2020).

2. Bull, F.; Goenka, S.; Lambert, V.; Pratt, M. Physical Activity for the Prevention of Cardiometabolic Disease. Dis. Control Priorities 2017, 5, 79-99.

3. Do, E.K.; Maes, H.H. Genotype $\times$ Environment Interaction in Smoking Behaviors: A Systematic Review. Nicotine Tob. Res. 2017, 19, 387-400. [CrossRef] [PubMed]

4. Golechha, M. Health promotion methods for smoking prevention and cessation: A comprehensive review of effectiveness and the way forward. Int. J. Prev. Med. 2016, 7. [CrossRef] [PubMed]

5. World Health Organization. WHO Global Report on Trends in Prevalence of Tobacco Smoking 2000-2025, 2nd ed.; World Health Organization: Geneva, Switzerland, 2018; 121p.

6. European Commission. Hungary Health Care. 2 October 2016, p. 19. Available online: https://ec.europa.eu/info/sites/info/ files/file_import/joint-report_hu_en_2.pdf (accessed on 8 March 2021).

7. Mathur, R.; Schofield, P.; Smith, D.; Gilkes, A.; White, P.; Hull, S. Is individual smoking behaviour influenced by area-level ethnic density? A cross-sectional electronic health database study of inner south-east London. ERJ Open Res. 2017, 3, 130-2016. [CrossRef]

8. Tombor, I.; Paksi, B.; Urbán, R.; Demetrovics, Z. Epidemiology of smoking in the Hungarian population, based on national representative data. Clin. Exp. Med. J. 2010, 4, 27-37. [CrossRef]

9. Kósa, Z.; Széles, G.; Kardos, L.; Kósa, K.; Németh, R.; Országh, S.; Fesus, G.; McKee, M.; Adany, R.; Voko, Z. A comparative health survey of the inhabit-ants of Roma settlements in Hungary. Am. J. Public Health 2007, 97, 853-859. [CrossRef] 
10. Škarić-Jurić, T.; Klarić, I.M.; Narančić, N.S.; Drmić, S.; Salihović, M.P.; Lauc, L.B.; Milicić, J.; Barabalić, M.; Zajc, M.; Janićijević, B. Trapped between Tradition and Transition-Anthropological and Epidemiological Cross-sectional Study of Bayash Roma in Croatia. Croat. Med. J. 2007, 48, 708-719. [PubMed]

11. Paulik, E.; Nagymajtényi, L.; Easterling, D.; Rogers, T. Smoking behaviour and attitudes of Hungarian Roma and non-Roma population towards tobacco control policies. Int. J. Public Health 2011, 56, 485-491. [CrossRef] [PubMed]

12. Sándor, J.; Kósa, Z.; Boruzs, K.; Boros, J.; Tokaji, I.; McKee, M.; Adany, R. The decade of Roma Inclusion: Did it make a difference to health and use of health care services? Int. J. Public Health 2017, 62, 803-815. [CrossRef] [PubMed]

13. Vokó, Z.; Csépe, P.; Németh, R.; Kósa, K.; Kósa, Z.; Széles, G.; Adany, R. Does socioeconomic status fully mediate the effect of ethnicity on the health of Roma people in Hungary? J. Epidemiol. Community Health 2009, 63, 455-460. [CrossRef]

14. Hajdu, T.; Kertesi, G.; Kézdi, G. Health Differences at Birth between Roma and non-Roma Children in Hungary: Long-run Trends and Decomposition. Popul. Dev. Rev. 2019, 45, 631-657. [CrossRef]

15. Balázs, P.; Grenczer, A.; Rákóczi, I.; Foley, K.L. Continued smoking versus spontaneous quitting among pregnant women living in a high risk environment. Cent. Eur. J. Public Health 2018, 26, 164-170. [CrossRef] [PubMed]

16. Loring, B. Tobacco and inequities. In Guidance for Addressing Inequities in Tobacco-Related Harm; World Health Organization: Geneva, Switzerland, 2014.

17. Carreras-Torres, R.; Johansson, M.; Haycock, P.C.; Relton, C.L.; Smith, G.D.; Brennan, P.; Martin, R.M. Role of obesity in smoking behaviour: Mendelian randomisation study in UK Biobank. BMJ 2018, 361, k1767. [CrossRef] [PubMed]

18. Soltész, B.; Pikó, P.; Sándor, J.; Kósa, Z.; Ádány, R.; Fiatal, S. The genetic risk for hypertension is lower among the Hungarian Roma population compared to the general population. PLoS ONE 2020, 15, e0234547. [CrossRef] [PubMed]

19. Ádány, R.; Pikó, P.; Fiatal, S.; Kósa, Z.; Sándor, J.; Bíró, É.; Kósa, K.; Paragh, G.; Bácsné Bába, É.; Veres-Balajti, I.; et al. Prevalence of Insulin Resistance in the Hungarian General and Roma Populations as Defined by Using Data Generated in a Complex Health (Interview and Examination) Survey. Int. J. Environ. Res. Public Health 2020, 17, 4833. [CrossRef]

20. Caporaso, N.; Gu, F.; Chatterjee, N.; Sheng-Chih, J.; Yu, K.; Yeager, M.; Chen, C.; Jacobs, K.; Wheeler, W.; Landi, M.T.; et al. Genome-wide and candidate gene asso-ciation study of cigarette smoking behaviors. PLoS ONE 2009, 4, e4653. [CrossRef] [PubMed]

21. Lessov-Schlaggar, C.N.; Pergadia, M.L.; Khroyan, T.V.; Swan, G.E. Genetics of nicotine dependence and pharmacotherapy. Biochem. Pharmacol. 2008, 75, 178-195. [CrossRef]

22. Li, M.D.; Ma, J.Z.; Payne, T.J.; Lou, X.Y.; Zhang, D.; Dupont, R.T.; Elston, R.C. Genome-wide linkage scan for nicotine depend-ence in European Americans and its converging results with African Americans in the Mid-South Tobacco Family sample. Mol. Psychiatry 2008, 13, 407-416. [CrossRef]

23. Pikó, P.; Fiatal, S.; Kósa, Z.; Sándor, J.; Ádány, R. Genetic factors exist behind the high prevalence of reduced high-density lipoprotein cholesterol levels in the Roma population. Atherosclerosis 2017, 263, 119-126. [CrossRef]

24. Chen, L.S.; Saccone, N.L.; Culverhouse, R.C.; Bracci, P.M.; Chen, C.H.; Dueker, N.; Han, Y.; Huang, H.; Jin, G.; Kohno, T.; et al. Smoking and genetic risk vari-ation across populations of European, Asian, and African American ancestry-a meta-analysis of chromo-some 15q25. Genet. Epidemiol. 2012, 6, 340-351. [CrossRef]

25. Ware, J.J.; Van den Bree, M.B.M.; Munafò, M.R. Association of the CHRNA5-A3-B4 Gene Cluster With Heaviness of Smoking: A Meta-Analysis. Nicotine Tob. Res. 2011, 13, 1167-1175. [CrossRef]

26. European Commission. Roma Health Report. Health Status of the Roma Population. Data Collection in the Member States of the European Union; European Commission: Brussels, Belgium, 2014; pp. 1-152. [CrossRef]

27. Kósa, Z.; Moravcsik-Kornyicki, Á.; Diószegi, J.; Roberts, B.; Szabó, Z.; Sándor, J.; Ádány, R. Prevalence of metabolic syndrome among Roma: A comparative health examination survey in Hungary. Eur. J. Public Health 2014, 25, 299-304. [CrossRef]

28. Fiatal, S.; Tóth, R.; Moravcsik-Kornyicki, Á.; Kósa, Z.; Sándor, J.; McKee, M.; Ádány, R. High Prevalence of Smoking in the Roma Population Seems to Have No Genetic Background. Nicotine Tob. Res. 2016, 18, 2260-2267. [CrossRef]

29. Hiscock, R.; Bauld, L.; Amos, A.; Fidler, J.A.; Munafò, M. Socioeconomic status and smoking: A review. Ann. N. Y. Acad. Sci. 2012, 1248, 107-123. [CrossRef]

30. Purcell, S.; Neale, B.; Todd-Brown, K.; Thomas, L.; Ferreira, M.A.R.; Bender, D.; Maller, J.; Sklar, P.; de Bakker, P.I.W. PLINK: A toolset for whole-genome association and population-based linkage analysis. Am. J. Hum. Genet. 2007, 81. [CrossRef]

31. IBM SPSS Statistics for Windows; Version 25; IBM Corporation: Armonk, NY, USA, 2017.

32. Bierut, L.J.; Madden, P.A.F.; Breslau, N.; Johnson, E.O.; Hatsukami, D.; Pomerleau, O.F.; Swan, G.E.; Rutter, J.; Bertelsen, S.; Fox, L.; et al. Novel genes identified in a high-density genome wide association study for nicotine dependence. Hum. Mol. Genet. 2007, 16, 24-35. [CrossRef]

33. Liu, J.Z.; Tozzi, F.; Waterworth, D.M.; Pillai, S.G.; Muglia, P.; Middleton, L.; Berrettini, W.; Knouff, C.W.; Yuan, X.; Waeber, G.; et al. Meta-analysis and imputation re-fines the association of 15q25 with smoking quantity. Nat. Genet. 2010, 42, 436-440. [CrossRef]

34. Thorgeirsson, T.E.; Gudbjartsson, D.F.; Surakka, I.; Vink, J.M.; Benjamin, D.; Geller, F.; Sulem, P.; Rafnar, T.; Esko, T.; Amin, N.; et al. Sequence variants at CHRNB3-CHRNA6 and CYP2A6 affect smoking behavior. Nat. Genet. 2010, 42, 448-453. [CrossRef] [PubMed]

35. Furberg, H.; Kim, Y.; Dackor, J.; Boerwinkle, E.; Franceschini, N.; Ardissino, D. Genome-wide meta-analyses identify multiple loci associated with smoking behavior. Nat. Genet. 2010, 42, 441-447. 
36. Saccone, S.F.; Hinrichs, A.L.; Saccone, N.L.; Chase, G.A.; Konvicka, K.; Madden, P.A.F.; Breslau, N.; John, E.O.; Hatsukami, D.; Pomerleau, O.; et al. Cholinergic nicotinic receptor genes implicated in a nicotine dependence association study targeting 348 candidate genes with 3713 SNPs. Hum. Mol. Genet. 2007, 16, 36-49. [CrossRef]

37. Mohd Saleem, S. Modified Kuppuswamy socioeconomic scale updated for the year 2019. Indian J. Forensic Community Med. 2019, 6, 1-3. [CrossRef]

38. Orton, L.; de Cuevas, R.A.; Stojanovski, K.; Gamella, J.F.; Greenfields, M.; La Parra, D.; Marcu, O.; Matras, Y.; Donert, C.; Frost, D.; et al. Roma populations and health inequalities: A new perspective. Int. J. Hum. Rights Healthc. 2019, 12, 319-327. [CrossRef]

39. Lau, A.Y.H.; Ridge, M. Addressing the impact of social exclusion on mental health in Gypsy, Roma, and Traveller communities. Ment. Health Soc. Incl. 2011, 15, 129-137. [CrossRef]

40. Stevens, V.L.; Bierut, L.J.; Talbot, J.T.; Wang, J.C.; Sun, J.; Hinrichs, A.L.; Thun, M.J.; Goate, A.; Calle, E.E. Nicotinic receptor gene variants influence susceptibility to heavy smoking. Cancer Epidemiol. Biomark. Prev. 2008, 17, 3517-3525. [CrossRef]

41. Rosicova, K.; Geckova, A.M.; Van Dijk, J.P.; Rosic, M.; Zezula, I.; Groothoff, J.W. Socioeconomic indicators and ethnicity as determinants of regional mortality rates in Slovakia. Int. J. Public Health 2009, 54, 274-282. [CrossRef]

42. Rosicova, K.; Reijneveld, S.A.; Geckova, A.M.; Stewart, R.E.; Rosic, M.; Groothoff, J.W.; Van Dijk, J.P. Inequalities in mortality by socioeconomic factors and Roma ethnicity in the two biggest cities in Slovakia: A multilevel analysis. Int. J. Equity Health 2015, 14, 1-10. [CrossRef]

43. Giuseppe, G.; Giulia, C.; Valentina, M.; Maria, M.; Gianluigi, F.; Alessandro, C. Socioeconomic and regional inequalities in smoking cessation in Italy, 2014-2017. Epidemiol. Prev. 2019, 43, 275-285.

44. Babinská, I.; Gecková, A.M.; Jarčuška, P.; Pella, D.; Mareková, M.; Štefková, G.; Veselská, Z.D. Does the Population Living in Roma Settlements Differ in Physical Activity, Smoking and Alcohol Consumption from the Majority Population in Slovakia? Cent. Eur. J. Public Health 2014, 22, S22-S27. [CrossRef] [PubMed]

45. Roberts, B.; Chikovani, I.; Makhashvili, N.; Patel, V.; McKee, M. Tobacco Use and Nicotine Dependence among Conflict-Affected Men in the Republic of Georgia. Int. J. Environ. Res. Public Health 2013, 10, 2185-2197. [CrossRef]

46. Sárváry, A.; Kósa, Z.; Jávorné, R.E.; Gyulai, A.; Takács, P.; Sándor, J.; Sárváry, A.; Németh, Á.; Halmai, R.; Ádány, R. Socioeconomic status, health related behaviour, and self-rated health of children living in Roma settlements in Hungary. Cent. Eur. J. Public Health 2019, 27, 24-31. [CrossRef] [PubMed]

47. Petek, D.; Pavlic, D.R.; Svab, I.; Lolić, D. Attitudes of Roma toward smoking: Qualitative study in Slovenia. Croat. Med. J. 2006, 47, 344-347. [PubMed]

48. Heffner, J.L.; Anthenelli, R.M.; Adler, C.M.; Strakowski, S.M.; Beavers, J.; DelBello, M.P. Prevalence and correlates of heavy smoking and nicotine dependence in adolescents with bipolar and cannabis use disorders. Psychiatry Res. 2013, 210, 857-862. [CrossRef] [PubMed]

49. Fagerström, K.O.; Kunze, M.; Schoberberger, R.; Breslau, N.; Hughes, J.R.; Hurt, R.D. Nicotine dependence versus smoking prevalence: Comparisons among countries and categories of smokers. Tob. Control 1996, 5, 52-56. [CrossRef]

50. Piasecki, T.M.; Piper, M.E.; Baker, T.B. Refining the tobacco dependence phenotype using the Wisconsin Inventory of Smoking Dependence Motives: II. Evidence from a laboratory self-administration assay. J. Abnorm. Psychol. 2010, 119, 513-523. [CrossRef]

51. Shiffman, S.; Waters, A.J.; Hickcox, M. The Nicotine Dependence Syndrome Scale: A multidimensional measure of nicotine dependence. Nicotine Tob. Res. 2004, 6, 327-348. [CrossRef] [PubMed] 